\title{
A NEW APPROACH TO UNDERSTANDING LABOUR SUPPLY OF DISABLED PEOPLE
}

The effects of job-type characteristics on participation decisions.

\section{Patricia Moreno, Juan M. Rodríguez-Póo, David Cantarero*}

July 21, 2017

\begin{abstract}
The main interest of this paper is to propose an individual utility maximization model to explain the low participation of disabled people. We account for heterogeneity of preferences and furthermore time of self caring for disabled individuals is considered as an argument in the utility function. The hours of work decided by disabled individuals are neither homogeneous (they depend on unknown characteristics) nor continuous (discrete choice sets). We use data of 4790 households from the Spanish Survey of Disability, Personal Autonomy and Dependency and find association between time of informal care and labour participation and consequently, the choice between jobs ${ }^{1}$.
\end{abstract}

Key words: Disability, informal care, labour supply hours, nested logit model.

JEL classification: J2, J22, I1, I12.

*All authors are members of the Department of Economics, University of Cantabria, Avd. de los Castros s/n, 39005-Santander. Spain. Juan Rodriguez is also member of the Université de Genève.

${ }^{1}$ The authors acknowledge financial support from the Programa Estatal de Fomento de la Investigacin Cientfica y Tcnica de Excelencia/ Spanish Ministery of Economy and Competitiveness. Ref. ECO201348326-C2-2-P. 


\section{Introduction}

The main interest of this paper is to explain both the low participation rate and the small percentage of disabled people that joins the labour force. To drive it, we propose to develop an individual utility maximization framework. This model accounts for heterogeneity of preferences and it considers self-care time for disabled individuals as an argument included in the individual utility function. The basic idea is that people with some health conditions and taking prescription medications may not be able to work full-time or in shifts jobs. It is necessary to take into account that disabled people require more time for selfcare than non-disabled people and they have different preferences about time assignations.

According to the Observatory of Disability and Labor Market in Spain (ODISMET), during the period of $2008-2009$, only $28 \%$ of disabled people had a job. This ratio is below the OECD average, which was $32 \%$. On the contrary, if we look at the participation rate, according to the Spanish National Bureau of Statistics (INE), only 36.6\% of disabled people participated in the labour market in that period, about 40 points lower than population without disability. These facts are a clear challenge to theorists and applied economists to explain these discrepancies both in terms of participation and employment rates. There is not only Active Labor Market Policies (ALMP) that have an impact on labour integration but also other variables such as workplace accessibility, education level for disabled people, etc. Thus, the results obtained in the paper should be of great interest for organizations of disabled people that are working both to ensure their labour integration and to promote changes in the employment opportunities for disabled people.

Activity and occupation rates among disabled people are really worrying, so the first of our goals is to analyse the causes of this low participation. Traditionally, low partici-

pation rates associated with disabled people have been explained from supply side (e.g., Livermore et al. (2000)). Not only standard costs in the employment search are important. People with disabilities often incur in additional costs for transport, rehabilitation, assistance, etc. All those circumstances may reduce their labour participation rate. Disability may affect participation raising the shadow wage due to economic public transfers related to disability (Madden (2004)).

Greve (2009), in the report for the Academic Network of European Disability Experts, pointed out that most countries pursue active strategies to integrate disabled people in the labour market. However, the success of these policies is not always evaluated. As an example of legislation, these report highlights the flex-jobs in Denmark that help to make it possible for people without full-work ability to enter the labour market. Additionally, Parodi and Scuilli (2008) applying a logit model carried out a labour participation model in households with disabled persons. In order to increase the income of the households with disabled members they explained policy recommendations such as the provision of 
care services and structural policies to improve employment.

However, standard approaches in individual maximization utility approach fail to consider several problems that are rather relevant when modeling participation decisions of disabled people (Schur (2003)). We assume that people with some declared disability (physical or psychical) need more time to improve their health; that is they have to go to medical consultations, rehabilitation or do specific exercises with more frequency than non-disabled people. This requires time, so we think that the preferences in time uses are different having disabilities or not (see Jones (2008) for a more detailed survey). Indeed, previous studies consider too simple discrete choice models where, as an outcome, disabled people plan either not to work or to work a number of hours that is a continuous function of the offered wages. Unfortunately, other unobservable issues different from the wage and other individual characteristics in a labour participation model exists, such as location, accessibility or flexibility of the job. This set of unknown characteristics can create discontinuities in the labour supply and desired working hours will not depend only on offered wages, but also in those non-observed factors of each job-type that affect the utility function for disabled people.

In this paper, we consider a more general model where the heterogeneity in preferences between individuals is included. We suppose that individuals are not free to choose the working hours because labour markets are rigid. They only can choose between jobs which are seen as sets of several characteristics, one of which is effectively the timetable. Then, in order to allow for discreteness in labour supply functions we propose to use the framework developed in Dagsvik $(1994)^{2}$. During the last few years, this approach and its extensions have been increasingly popular as in Van Soest (1995), who offers an alternative approach in which the number of working hours were discretised and the error term was supposed to have an extreme value distribution. Assuming random utility maximization, he obtained the multinomial logit model (see McFadden (1984)). The same idea was proposed in a different framework, for nurses, (e.g.,Saether (2004) and Di Tommaso et al. (2009)) or for married women (Aaberge et al. (1999) and Dagsvik and Strom (2006)). Also, for married women, Aaberge (1995) used simulation techniques to build the choice set.

An additional problem that the previous models present when dealing with disabled people's behaviour is that one may end up using empirical models where the decision of participation or not in the labour market is considered at the same level as the individual's decision on their labour supply. In statistical and empirical studies these models are specified as multinomial logit ones and in order to implement inference, it is necessary to assume the Independence of Irrelevant Alternatives property (IIA). Unfortunately, we be-

\footnotetext{
${ }^{2}$ He proposed a discrete choice framework in which the agent's choice problem is based on the choice among feasible jobs and the distribution of desired working hours is discrete due to the choice opportunities distribution.
} 
lieve that in these models, this assumption is not correct because some of the alternatives are more closely related than others. Hence, to solve it we propose using the so-called nested logit model where the individual decision is divided in two steps. In the first one, individuals maximize their utility by choosing to participate or not in the labour market while in the second one, they choose their ideal job type conditioned on participation.

We use data from the Spanish Survey on Disability, Personal Autonomy and Dependency Situations (2008). This survey is the most recent source of information about disability in Spain having detailed information about disabled people and their families.

The rest of the paper is organized as follows. We start with a presentation of our approach applying a random utility model, detailing the specification (based on supply side), the method and variables used. Then, we present the empirical results and we conclude summarizing the main findings, policy implications and possible directions for further research.

\section{Methods}

Let $U_{n}\left(G_{i}, t c_{i}, b_{i}\right)$ be the utility function for a disabled person $n$, choosing the job-alternative $i$. Here $i=1$ if there is no participation, $i=2$ if working full-time, $i=3$ if working parttime and $i=4$ if working shift job (includes both long-term night shifts and work schedules in which employees change or rotate shifts). Besides, $G$ is the disposable income corresponding to job $i, t c$ is the time per day devoted to informal care (such as rehabilitation, doing exercise, tidiness...) for the disabled person in this alternative, and $b_{i}$ are other characteristics conforming the job type. For given working hours, the budget constraint for a household is defined as:

$$
G_{i}=f\left(w h_{i}, I\right)
$$

where $h_{i}$ is the working time associated with job $i, w$ is the wage per hour and $I$ is the non-labour income for disabled people, which also includes the wages of the rest of the household members and other income. $f($.$) is a general function which describes the$ transformation of gross income into after-tax income and $s$ are some characteristics of the disabled person. We also know that time is limited so, $h_{i}+t c_{i}=T$.

Traditionally, theoretical models of utility assumed that all nonmarket time was leisure, $L_{i}$, but nowadays there is a huge body of literature extending the first proposal of Becker (1965) focusing on other time uses (such as housework time, childcare time or as is our case cares time) denoted by $t_{i}$. Therefore, in economic models including time allocations we need to realise that time is limited, so that it also exits a time restriction, as we show in our manuscript. In this regard, following the seminal paper of Grossman (1972) and the posterior extension of ? to a lifecycle investment framework, health can be considered 
a capital stock which is subject a depreciation over time. These authors suggested that people may produce their own health by using resources and time. Thus, some practices such as doing exercise, rehabilitationare time consuming activities but are also associated with a better health. Then, health is a consumption good because increase the utility of individuals and also an inversion good because increase their productivity. The investment in health depends on actual status of health, so is logical to think that this investment has to be increased with age or when health is worse like in the case of disabled or people with limitations. Hence, Grossman's model is then especially useful when studying disabled people, for whom the time investment in cares to maintain good health is really important. In that sense, there exists some studies, as is our case, focusing on activities such as medical care or personal self-care Ettner et al. (2009). More recently, Mazzocchi and Traill (2011) also include factors affecting health in the utility function. In this sense, and taking into account that we are studying disabled people, we consider that Health is a function of the time devoted to cares. What we meant is that more time affects positively the health, so it is a source of welfare. Then, it is more valuable for those with worst health because they need to invest more time for improving it and also for older people. Besides Kyung et al. (2013) also specified health as a function of informal care.

The omission of leisure time in our model is partly due to the difficulty in separating care time and leisure for disabled people, taking into account the large number of borderline cases. A similar point of view was assumed in ${ }^{15}$, where it is pointed out the difficulty of separating leisure and child-care using as borderline case the time for playing with a child in the case of married women. Because we do not observe all variables affecting the preferences, we assume the utility function to be random, thus;

$$
U_{n}\left(G_{i}, t c_{i}, b_{i} ; s\right)=v_{n}\left(G_{i}, t c_{i} ; s\right)+\epsilon\left(b_{i}\right) .
$$

Where $i \in J[J=1,2,3,4]$ and $b_{i} \in B\left[B=b_{1}, b_{2}, b_{3}, b_{4}\right]$.

$v($.$) is a positive deterministic function and \epsilon\left(b_{i}\right)$ is a random component for unobserved characteristics that affect the utility assumed to be independent and identically extreme value distributed with a probability distribution function such as:

$$
\operatorname{Pr}\left(\epsilon\left(b_{i}\right) \leq x\right)=e^{-e^{-x}}
$$

We will assume that individual $n$ makes an election because the job-alternative chosen, $i$ , maximizes its utility given other characteristics, that is:

$$
U_{n}\left(G_{i}, t c_{i}, b_{i} ; s\right)>U_{n}\left(G_{j}, t c_{j}, b_{j} ; s\right) \quad i, j \in J .
$$

Due to preferences not completely known to us, the best we can do in simulating the behaviour of a disabled person is to calculate the probability of choosing a job type category, given the characteristics and the available alternatives ${ }^{3}$. The probability that individual

\footnotetext{
${ }^{3}$ For more details of this type of modeling see Dagsvik and Strom (2004)
} 
$n$ chooses job-type $i$, would be:

$$
P\left(U_{n} \mid G_{i}, t c_{i}, b_{i} ; s\right)=\max _{j \in J} U_{n}\left(G_{j}, t c_{j}, b_{j} ; s\right)
$$

Given the assumed probability distribution for the error term, we will get the multinomial logit model.

$$
\left.P\left(U_{n} \mid G_{i}, t c_{i}, b_{i} ; s\right)\right)=\frac{\exp \left(v_{n}\left(\left(G_{i}, t c_{i}, b_{i} ; s\right)\right)\right.}{\sum_{j=i}^{J} \exp \left(v_{n}\left(\left(G_{j}, t c_{j}, b_{j} ; s\right)\right)\right.} .
$$

This model, which is the most commonly used assumes that the choice from a given set of alternatives satisfies the IIA. This property implies that random elements in utility are independent across alternatives and identically distributed. IIA property avoids including heterogeneity in preferences and correlation between alternatives. Those impositions may result too restrictive in our study, in which three of the alternatives are referred to labour participation and the other one not, so we are going to relax it. Thus, we construct a two level model with a degenerate branch; the upper level is a participation and nonparticipation nest, while the lower level is composed of the three kind of jobs corresponding to the participation nest. Then,

$$
U_{n}\left(J=i \mid p, G_{i}, t c_{i}, b_{i} ; s\right)=U_{n}\left(p \mid G_{j}, t c_{j}, b_{j} ; s\right)+U_{n}\left(J=i \mid p, G_{i}, t c_{i}, b_{i} ; s\right) .
$$

In a first step, the disabled person choose to belong to a nest $m$ from two available (to participate in labour market, $p$ or not, $p_{0}$ ). For evaluating this first choice, they compare $w *$, which is the shadow price of the time out of the market with market wage. This shadow time is non-observable to us but we observe that when $w^{*}>w$ there is no participation $\left(m^{\prime}=p_{0}\right)$. Consequentially, the household would choose alternative $i=1$, but if $w^{*} \leq w$ then they participate $\left(m^{\prime}=p\right)$, then choose the alternative which maximizes the utility from $i=2,3,4$. Then they have, as a starting point, two possible solutions: a corner $\left(i=1 \in p_{0}\right)$ and a three interior ones $(i=2,3,4 \in p)$.

In the nested model we need to add an additional parameter to the joint distribution of the error terms in each nest, $\lambda_{m}$. This parameter represents a measure of the correlation of the random components of the alternatives belonging to that nest. So that, the utilities are re-scaled by the inverse of the mentioned dissimilarity parameter, $\lambda_{m}$ attached to an index variable called Inclusive Value (IV) which is defined by a set of utility expressions associated with a partitioned set of alternatives. That idea lies in the grouping of similar alternatives into nests and thus creating a hierarchical structure of those alternatives (Ben-Akiva and Lerman (1985) and Train (2003)). In our case, the IV for the nest implying participation, $p\left(I V_{p}\right)$ is defined as:

$$
I V_{p}=\lambda_{p}=\operatorname{Ln} \sum_{j \in p} e^{v_{n j} / \lambda_{p}}=\operatorname{Ln}\left[e^{\left(v_{n 2} / \lambda_{p}\right)+\exp \left(v_{n 3} / \lambda_{p}\right)+\exp \left(v_{n 4} / \lambda_{p}\right)}\right] .
$$


Then, the probability that a person chooses an alternative can be written as:

$$
\begin{aligned}
& \quad P\left(J=i \mid i \in p, G_{i}, t c_{i}, b_{i} ; s\right)= \\
& =\quad \frac{\exp \left(v_{n p}\left(f\left(w h_{j}, I\right), t c_{j}, b_{j} ; s\right)+\frac{\lambda_{p}}{\lambda_{j}} \sum_{j=2}^{4} \exp \left(v_{n j \mid p}\left(f\left(w h_{j}, I\right), t c_{j}, b_{j} ; s\right) / \lambda_{p}\right.\right.}{\sum_{m^{\prime} \in m} \exp \left(\left(v_{n m^{\prime}}\left(f\left(w h_{k}, I\right), t c_{k}, b_{k} ; s\right)+\frac{\lambda_{m}^{\prime}}{\lambda_{k}} \sum_{j=2}^{4} \exp \left(v_{n k \mid p}\left(f\left(w h_{k}, I\right), t c_{k}, b_{k} ; s\right) / \lambda_{m^{\prime}}\right.\right.\right.} \\
& \times \quad \frac{\exp \left(v_{n i \mid p}\left(f\left(w h_{i}, I\right), t c_{i}, b_{i} ; s\right) / \lambda_{p}\right.}{\sum_{j=2}^{4} \exp \left(v_{n j \mid p}\left(f\left(w h_{j}, I\right), t c_{j}, b_{j} ; s\right) / \lambda_{p}\right.} .
\end{aligned}
$$

We must take into account that we have a degenerate branch. It means that the IV for the non participation is 1 . If the property of IIA is satisfied, our model could be simplified to a multinomial logit.

\subsection{Model Specification and Estimation Procedure.}

The deterministic part of the utility function requires choosing a functional form, but this choice is not imposed directly by economic theory so it is usually determined by the data. The common approach in this context is to find a flexible family of parametric or semi-parametric specifications. Dagsvik and Strom (2006) demonstrate that under general regularity conditions, the systematic part of the utility function can have a form, similar to;

$$
v_{n}\left(G_{i}, t c_{i} ; s\right)=\beta_{G} \frac{G_{i}^{\alpha_{G}}-1}{\alpha_{g}}+\beta(s) \frac{t c_{i}^{\alpha_{t c}}-1}{\alpha_{t c}} .
$$

Where $\beta\left(s_{n}\right)=\beta_{0}+\beta_{1} X_{1}+\beta_{2} X_{2}+\beta_{3} X_{3}$

The explicative variables included in our study are: $x_{1}=$ Age, $x_{2}=1$ if the person with disability is a man and $x_{3}=$ Limitation grade of the person with disability. We also assume that $v_{n}\left(G, t_{c} ; s\right)$ is additive separable in income and care time and each utility component is supposed to have a Box-Cox functional form. In that sense, we take the advantage of having an specification which is globally concave. For the utility function to be quasi-concave, we require $\alpha_{G}<1$ and $\alpha_{t c}<1$. Note that if $\alpha_{G} \rightarrow 0$ and $\alpha_{t c} \rightarrow 0$, the utility function converges to a log-linear function.

This model could be estimated sequentially but there is a considerable loss of information resulting in inefficient estimation, $\left(\right.$ see $\left.^{18}\right)$. So, we use the full-information maximum likelihood which is efficient and its expression for a nested model is formalized as:

$$
\log L=\sum_{n=1}^{N} \sum_{i \in J} \delta_{n}(J=i) \log \left[P\left(J=i / G_{i}, t c_{i}, s, \beta, \lambda\right] .\right.
$$

Where $n=1, \ldots, N$ are observations, $i \in J$ are the available alternatives, $\lambda$ is the parameter estimated for the inclusive value, $s$ are the exogenous attributes and $\beta$ their utility parameters. $\delta_{n}(J=i)=1$ if the alternative $i$ is chosen and zero otherwise. 


\subsection{Data}

The available surveys on disability in Spain cover most of the needs for information of disability, dependency, ageing and the population health ${ }^{4}$. People with disability is defined as those who reported to have at least a deficiency; that does not always imply having limitations on the development of daily activities.

According to the Survey on Disability, Personal Autonomy and Dependency Situations 2008 , in Spain, of the 7.4 million old people (more than 65 years old), 2,227,500 declared a disability in 2008, representing the $30.3 \%$. The overall disability rate stands at $8.5 \%$, with an absolute value of 3,847,900 people with disabilities, of which 1,547,300 are men $(40 \%)$ and 2,300,500 women $(60 \%)$. It should be noted that the age range in which most people with disabilities fall are between 55 and 64 years (14.18\% of the total).

\footnotetext{
${ }^{4}$ Three surveys have been carried out: the Survey on Disabilities, Deficiencies and Disabilities (EDDM1986), the Survey on Disabilities, Deficiencies and State of Health (EDDS1999) and the Survey on Disability, Personal Autonomy and Dependency Situations 2008.
} 
Table 1: Main results of the Survey on Disability, Personal Autonomy and Dependency Situations 2008.

\begin{tabular}{|l|l|}
\hline Total Survey & \\
\hline Total Sample. Households & 96075 \\
\hline People who answered the questionnaire & 22795 \\
\hline $\begin{array}{l}\text { People with limitations who answered the ques- } \\
\text { tionnaire }\end{array}$ & 14706 \\
\hline People with limitations who have a job & 1632 \\
\hline People with limitations who work : & $41.4 \%$ Friends/Family; 22.9\% Firm recruitment; \\
How did you find your current job? & $2.62 \%$ public service of employment; $1.15 \%$ disabil- \\
& ity association \\
\hline $\begin{array}{l}\text { People with limitations. Are you looking for a } \\
\text { job? (<65 years old) }\end{array}$ & $10.16 \%$ (610) \\
\hline Why do you think you cant find a job? & $43.65 \%$ (of the $10.16 \%$ ) for the disability \\
\hline Why don't you look for a job? & $23.85 \%$ think it is difficult because of the disability; \\
& $50 \%$ can't work \\
\hline $\begin{array}{l}\text { Do you feel discrimination in your job due to } \\
\text { your disability? }\end{array}$ & $9.42 \%$ \\
\hline $\begin{array}{l}\text { Do you feel discrimination when you are look- } \\
\text { ing for a job? }\end{array}$ & $20.8 \%$ \\
\hline
\end{tabular}

Source: Survey on Disability, Personal Autonomy and Dependency Situations 2008.

From the 14.706 individuals with limitations that answered the questionnaire (about disabilities) only 1632 were workers. Usually, the idea is that having a disability makes the individual not capable for any kind of work. This is totally unfounded and a true effort is necessary to match their capabilities with the labour market opportunities. We have restricted the 22795 disabled individuals for those with ages between 16 and $65 .{ }^{5}$

\footnotetext{
${ }^{5}$ In Spain there is a law based on the integration of Disabled People. This law of Social Integration of disabled people 13/1982 of the 7th of April (LISMI) established that for private and public firms with more than 50 workers, it was compulsory to hire at least a $2 \%$ of disabled people. Despite the existence of this regulations, there are very few companies that fulfill the obligation. According to the Academic Network of European Disability Experts, in Spain only 14\% of business larger than 50 workers meet the requirements in 2008
} 
Table 2: Frequencies for each type of job depending on level of limitations.(\%)

\begin{tabular}{|l|l|l|l|l|}
\hline Choices & Total & $\begin{array}{l}\text { High level of } \\
\text { limitation }\end{array}$ & $\begin{array}{l}\text { Medium level of } \\
\text { limitation }\end{array}$ & $\begin{array}{l}\text { Without } \\
\text { limitation }\end{array}$ \\
\hline Non Participation & 52.02 & 81.49 & 71.02 & 30.4 \\
\hline Full-Time Job & 40.1 & 15.35 & 23.47 & 58.72 \\
\hline Part-Time Job & 6.22 & 2.66 & 4.6 & 8.4 \\
\hline Shifts & 1.6 & 0.4 & 0.9 & 2.4 \\
\hline Size & 19160 & 3308 & 6032 & 9820 \\
\hline
\end{tabular}

Source: Survey on Disability, Personal Autonomy and Dependency Situations 2008.

Table 3: Descriptive statistics (Means)

\begin{tabular}{|l|l|l|l|l|}
\hline Variables & Total & $\begin{array}{l}\text { High level of } \\
\text { limitation }\end{array}$ & $\begin{array}{l}\text { Medium level of } \\
\text { limitation }\end{array}$ & $\begin{array}{l}\text { Without } \\
\text { limitation }\end{array}$ \\
\hline Age (Years) & 50.8 & 52.19 & 52.57 & 49.25 \\
\hline Chronic Illness (Binary) & 0.78 & 0.85 & 0.83 & 0.73 \\
\hline Male (Binary) & 0.65 & 0.60 & 0.54 & 0.73 \\
\hline Working (Binary) & 0.48 & 0.185 & 0.29 & 0.69 \\
\hline $\begin{array}{l}\text { Time of Cares (Hours } \\
\text { per day) }\end{array}$ & 2.42 & 4.45 & 1.46 & 2.34 \\
\hline Size & 19160 & 3308 & 6032 & 9820 \\
\hline
\end{tabular}

Source: Survey on Disability, Personal Autonomy and Dependency Situations 2008.

These figures show the low participation between disabled people, specially for those with more limitations. About the $18 \%$ of people with limitations is working while this percentage is the $69 \%$ if the disable individual has no limitation. Also significant is the difference in the number of hours per day devoted to cares, which is the double in case of having severe limitations. 
Table 4: Estimated parameters of the utility function. Nested Logit

\begin{tabular}{|l|l|l|l|}
\hline Variable & Coefficient & $\begin{array}{l}\text { Standard } \\
\text { error }\end{array}$ & $b /$ St.Er. \\
\hline Disposable Income & $0.344^{* * *}$ & 0.080 & 4.29 \\
\hline$\alpha_{G}$ & -1.19 & & \\
\hline Care Time & $-2.409^{* * *}$ & 0.210 & -11.421 \\
\hline$\alpha_{t c}$ & 0.40 & & \\
\hline Non-participation & & & \\
\hline Age & $0.089^{* * *}$ & 0.005 & 17.576 \\
\hline Gender & $-0.268^{*}$ & 0.157 & -1.702 \\
\hline Limitation & $-0.827^{* * *}$ & 0.088 & -9.408 \\
\hline Full-time job & & & \\
\hline Age & $0.035^{* * *}$ & 0.006 & 5.314 \\
\hline Gender & 0.239 & 0.226 & 1.059 \\
\hline Limitation & $0.417^{* * *}$ & 0.119 & 3.481 \\
\hline Part-time job & & & \\
\hline Age & 0.011 & 0.007 & 1.578 \\
\hline Gender & 0.336 & 0.249 & 1.350 \\
\hline Limitation & $0.241^{*}$ & 0.131 & 1.836 \\
\hline$\lambda_{p}$ & $0.669^{* * *}$ & 0.059 & 11.290 \\
\hline Number of Observations & 19160 & & \\
\hline$R^{2}$ & 0.287 & & \\
\hline & & & \\
\hline
\end{tabular}

Source: Authors' elaboration from the Survey on Disability, Personal Autonomy and Dependency Situations 2008.

*** Significance at $1 \%$ level, ${ }^{* *}$ Significance at $5 \%$ level and ${ }^{*}$ Significance at $10 \%$ level.

\section{Results}

The maximum likelihood method is used to estimate the parameters of the nested logit model ${ }^{6}$. Tables 4 and 5 report the estimated parameters of the utility function according to the final specification of the model. For the nested logit model, we also report the estimate of $\lambda_{p}$ and its standard deviation.

The parameters $\alpha_{G}$ and $\alpha_{t c}$ are estimated to yield a quasi-concave utility function, both of them being less than 1 (-1.19 and 0.40 respectively). The results show a positive sign of the disposable income as we expected, because more income in the household is associated with higher utility. Then, they would prefer jobs reporting more earnings if all other factors are similar.

\footnotetext{
${ }^{6}$ We also estimate a multinomial logit in order to compare these two models
} 
We have tested other taste-modifying variables but we have selected those having more significant effects on preference for care time, and those were related with theoretical findings.

Care time has a negative sign, that is, as more time is devoted to care, less is the utility in the alternative chosen. This is related with the results obtained by Van den Berg et al. ${ }^{20}$, who found an overall negative correlation between care hours and well-being (utility). ${ }^{7}$ The positive sign for age shows a preference for care time when the age increases. Thus, people with disabilities prefer jobs which allow more care time when they get older ${ }^{8}$.

Non-participation is preferred to shift-work (base category) for older people, women and more limited people. As the individuals are less limited, they would prefer jobs allowing shorter care time. People with more level of limitation would have more preference for care time and prefer jobs that could allow that dedication. We also provide an estimate of McFadden's goodness of fit measure, which indicated that the model fits quite well. Most of variables are individually significant and the model is globally significant too.

\footnotetext{
${ }^{7}$ That can be explained by the direct relation between that variable and the poor health status that reduce welfare. It allows for less time for social relations and maybe more stress, causing less utility for the household in every alternative chosen.

${ }^{8}$ This may be caused by the fact that disabilities are more frequent in advanced ages and care time is more valued.
} 
Table 5: Discrete choice. Multinomial Logit

\begin{tabular}{|l|l|l|l|}
\hline Variable & Coefficient & $\begin{array}{l}\text { Standard } \\
\text { error }\end{array}$ & b/St.Er. \\
\hline Disposable Income & $2.596^{* * *}$ & 0.403 & 6.442 \\
\hline Care Time & $-2.521^{* * *}$ & 0.200 & -12.557 \\
\hline Non-participation & & & \\
\hline Age & $0.095^{* * *}$ & 0.006 & 15.011 \\
\hline Gender & -0.192 & 0.208 & -0.922 \\
\hline Limitation & $-0.770^{* * *}$ & 0.112 & -6.829 \\
\hline Full-time job & & & \\
\hline Age & $0.036^{* * *}$ & 0.006 & 5.914 \\
\hline Gender & 0.258 & 0.209 & 1.238 \\
\hline Limitation & $0.391^{* * *}$ & 0.110 & 3.546 \\
\hline Part-time job & & & \\
\hline Age & 0.006 & 0.007 & 0.925 \\
\hline Gender & $0.381^{*}$ & 0.238 & 1.603 \\
\hline Limitation & $0.246^{* *}$ & 0.125 & 1.967 \\
\hline Number of Observations & 4790 & & \\
\hline$R^{2}$ & 0.270 & & \\
\hline & & & \\
\hline
\end{tabular}

Source: Authors' elaboration from the Survey on Disability, Personal Autonomy and Dependency Situations 2008.

*** Significance at $1 \%$ level, ${ }^{* *}$ Significance at $5 \%$ level and ${ }^{*}$ Significance at $10 \%$ level.

Table 5 presents the results of multinomial logistic regression on job choices. As we observe, the results are similar to before. Working part or full time is preferred to working shifts for men, for those who have moderate or no limitation and also for those who are older. On the other hand, non-participation is preferred to shift-work if the individual is old, but is less preferred if the person has less limitations. Men also prefer to participate, even if it meant shift-work, rather than not participate.

We carried out the test developed by Hausman and McFadden (1984) to test the validity of the IIA assumption and we have to reject the null hypothesis of the IIA property. Then, the relevant model is not the multinomial logit model but the nested model. The degree of independence in unobserved utility among the upper nest is estimated to 0.67. Thus, our model satisfies the necessary condition in that it must be between 0 and 1 . The parameter is not 1 and corroborates our hypotheses that the nested logit model is better than the multinomial logit one. 
Table 6: Utilities for each kind of job

\begin{tabular}{|l|l|l|l|l|}
\hline & $\begin{array}{l}\text { Non- } \\
\text { partipation }\end{array}$ & Full-time & Part-time & Shifts \\
\hline Disposable Income & $5.77(1.26)$ & $5.25(1.30)$ & $5.22(1.16)$ & $5.27(1.16)$ \\
\hline Care Time & $1.01(0.56)$ & $0.96(0.59)$ & $1.00(0.60)$ & $0.88(0.60)$ \\
\hline Age & $54.85(32.41)$ & $45.76(29.65)$ & $46.82(29.10)$ & $45.70(31.42)$ \\
\hline Gender & $0.58(0.66)$ & $0.70(0.66)$ & $0.75(0.66)$ & $0.68(0.46)$ \\
\hline Limitation & $2.02(1.42)$ & $2.58(1.69)$ & $2.52(1.73)$ & $2.71(1.82)$ \\
\hline
\end{tabular}

Source: Authors' elaboration from the Survey on Disability, Personal Autonomy and Dependency Situations 2008.

Table 6 show a pondered average of the parameters of the utility function. Each attribute is weighted by the percentage of choices of that alternative and then all values from each alternative are summed up to obtain the average. People with disability who choose shiftwork are on average, the youngest. That result is logical with our intuition because this kind of job is less flexible and requires more effort than the others.

We consider that the results referred to care time are reasonable. People who devote more time to care chose non-participation more frequently. This alternative is followed by part-time jobs which also allow more time out of the labour market. We argue that conciliation between personal and professional life is more difficult for people undertaking shift-work or full-time jobs, and that is reflected in the data (people who choose to work shifts have the lowest figure of care time, 0.88). On average, people with more limitations (2.02) choose the non-participation alternative and contrarily, people working shifts are those having the minimum level (2.71) (remember the level 3 implies the less limitative).

For each observation we predict the job status for the person with disability in order to be the one having the highest estimated probability, and we calculate the number of observations for which the predicted status is equal to the actual status. In that sense, the results obtained about the prediction power of the model are encouraging. 
Table 7: Job-specific elasticities

\begin{tabular}{|l|l|l|}
\hline Type of job & $\begin{array}{l}\text { Total effect (increase in in- } \\
\text { come) }\end{array}$ & $\begin{array}{l}\text { Total effect (increase in care } \\
\text { time) }\end{array}$ \\
\hline Non- participation & 0.699 & -0.774 \\
\hline Full-time & -0.752 & 0.968 \\
\hline Part-time & -0.823 & 0.657 \\
\hline Shifts & -0.900 & 0.428 \\
\hline & & \\
\hline Non- participation & -0.318 & 0,418 \\
\hline Full-time & 0.780 & -0.953 \\
\hline Part-time & -0.827 & 0.379 \\
\hline Shifts & -0.699 & 0.482 \\
\hline & & \\
\hline Non- participation & -0.091 & 0.072 \\
\hline Full-time & -0.217 & 0.253 \\
\hline Part-time & 1.549 & -1.480 \\
\hline Shifts & -0.056 & 0.149 \\
\hline & & \\
\hline Non- participation & -0.045 & 0.021 \\
\hline Full-time & -0.077 & 0.055 \\
\hline Part-time & -0.154 & 0.065 \\
\hline Shifts & 1.569 & -0.860 \\
\hline & & \\
\hline
\end{tabular}

Source: Authors' elaboration from the Survey on Disability, Personal Autonomy and Dependency Situations 2008.

Our estimates suggest that policy makers have several tools to affect these choice variables, such as social policies and firms grants, to improve labour supply of people with disabilities changing their decisions. We note that when the income level related with nonparticipation increases by $1 \%$ the decision probability of this alternative increases about $0.7 \%$. The higher increase in the probability to choose an alternative associated with an income increment is the referent to shift-work. When the income associated with this alternative is raised by $1 \%$, then the probability of choice for that type of job increases by $1.56 \%$. 


\section{Discussion and Conclusion}

We have estimated a job-type model on Spanish data for a sample of households where a person with disability lives. Our approach differs from previous research because as far as we know, it is the first time that a model of labour supply for disabled people is estimated regarding job-types as a set enclosing several factors. Besides, the performance gains of our approach over previous studies is based on disabled people need more time for health care than people without disability and can affect their decisions. We suppose that a person with disability can require support or assistance for basic living activities and it varies depending on the age, individual needs, lifestyle and other circumstances which sometimes detract them from participating in the labour market. Consistent with this objective, we have carried out a discrete choice labour supply model in which conditioning on their participation in the labour market, they face a set of choices of their "job-alternatives". Therefore, a choice between participating or not is presented and afterwards, another between working in a full-time, part-time job or to work shifts.

By learning from the past and looking into the future, our approach has allowed us to learn about one important feature: an overall income increase seems to enhance the probability of working shifts and shows that non participation is the least flexible choice. Care time is more valuable with age and limitation-level, affecting the choice decisions about labour activities. This should not be very surprising in the model given that individuals are rational and have to choose between a set of job-packages that may not be as flexible as they want. Thus, policy makers should aim to try and connect older people and those with limitations with more flexible jobs which respect their care needs.

This paper clearly shows that a generalist policy against some types of jobs which could be undesirable in the overall population. People with disability have special needs and in most cases require more flexible jobs. Not only but offering telecommuting may be a good option for disabled people to develop their capabilities and competencies. Hence, it is necessary to promote policies for support in addressing the accommodation needs for disabled people, and consequently promoting their wellbeing. : In this sense, specific firms management and job placement agencies could help to overcome the existent barriers, being more flexible to establish a reasonable schedule for disabled people.

To sum up, further work is needed to evaluate health-care for people with disability and promote their hiring in more flexible jobs. All these issues requires more research in the future but this paper is a good start to undertake it. 


\section{Acknowledgements}

The authors also would like to thank all the people who have given us useful suggestions,

specifically the participants at the XXI Meeting of Public Economics, the XVIII Applied Economics Meeting and the XXXIII Health Economics Conference. 


\section{References}

Aaberge, R. (1995). "Choosing measures of inequality for empirical applications". Discussion Papers, 158 in Research Department of Statistics Norway.

Aaberge, R., U. Colombino, and S. Strom (1999). "Labor supply in italy: An empirical analysis of joint household decisions, with taxes and quantity constraints". Journal of Applied Econometrics 14(4), 403-422.

Becker, G. (1965). "A theory of the allocation of time". The Economic Journal 75(299), 493-517.

Ben-Akiva, M. and S. Lerman (1985). "Discrete choice analysis: Theory and application to travel demand". The MIT Press, Cambridge/Massachusetts.

Dagsvik, J. (1994). "Discrete and continuous choice, max-stable processes, and independence from irrelevant attributes". Econometrica 62(5), 1179-1205.

Dagsvik, J. and S. Strom (2004). "Sectoral labor supply, choice restrictions and functional form". Discussion Papers, 388 in Research Department of Statistics Norway.

Dagsvik, J. and S. Strom (2006). "Sectoral labor supply, choice restrictions and functional form". Journal of Applied Econometrics 21 (6), 803-826.

Di Tommaso, M., S. Strom, and E. Saether (2009). "Nurses wanted: Is the job too hard or is the wage too low". Journal of Health Economics 28, 748-757.

Ettner, S., B. Cadwell, L. Russell, A. Brown, A. Karter, M. Safford, C. Mangione, G. Beckles, W. Herman, and T. Thompson (2009). "Investing time in health: do socioeconomically disadvantaged patients spend more or less extra time on diabetesself-care?". Health Economics 18, 645-663.

Greve, B. (2009). "The labor market situations of disabled people in european countries and implementation of employment policies; a summary of evidence from country reports and research studies.". Report prepared for the Academic Network of European Disability Experts (ANED).

Grossman, M. (1972). "On the concept of health capital and the demand for health.". Journal of Political Economy 80, 223-255.

Hausman, J. and D. McFadden (1984). "Specification test for the multinomial logit model". Econometrica 52(5), 1219-1240.

Jones, M. (2008). "Disability and the labor market: a review of the empirical evidence.". Journal of Economic Studies 35(5), 405-424.

Kyung, Y., E. Norton, S. Stearns, and C. Van Houtven (2013). "Informal care and caregivers health.". Health Economics 24, 224-237. 
Livermore, G., D. Stapleton, and D. Wittemburg (2000). "The economics of policies and programs affecting the employment of people with disabilities". Discussion Papers, 5 in http://www.ilr.cornell.edu/RRTC/papers.html.

Madden, D. (2004). "Labor market discrimination on the basis of health: An application to uk data.". Applied Economics 36(5), 421-442.

Mazzocchi, M. and W. Traill (2011). "Calories, obesity and health in oecd countries". Applied Economics 43(26), 3919-3929.

McFadden, D. (1984). "Econometric analysis of qualitative response models", Volume 2. Handbook of Econometrics, in: Z. Griliches and M. D. Intriligator.

Parodi, G. and D. Scuilli (2008). "Disability in italian households: income, poverty and labour market participation.". Applied Economics 40(20), 2615-2630.

Saether, E. (2004). "Nurses' labor supply with an endogenous choice of care level and shift type : a nested discrete choice model with nonlinear income". University of Oslo, Norway.

Schur, L. (2003). "Barriers or oppportunities? the causes of contingent and part-time work among people with disabilities.”. Industrial Relations 42, 589-622.

Train, K. (2003). "Discrete choice methods with simulation". Cambridge University Press.

Van Soest, A. (1995). "Discrete choice models of family labor supply". Journal of Human Resources 30, 63-88. 